\title{
Historia de la Arqueología del México Antiguo
}

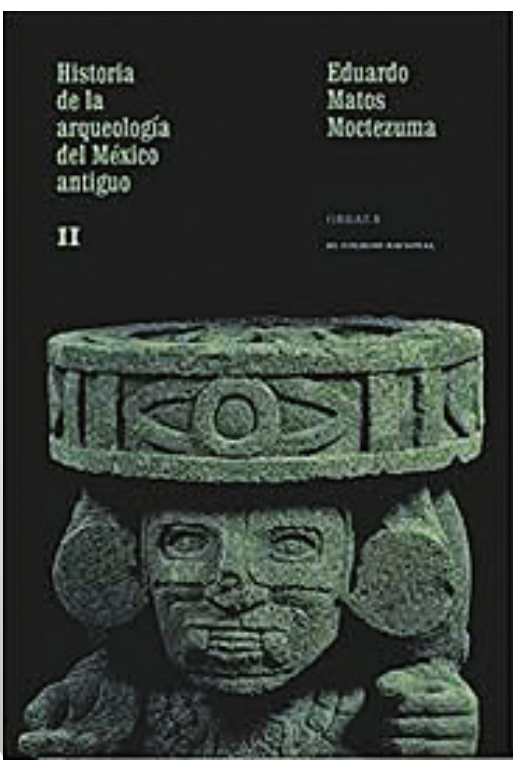

FICHA BIBLIOGRÁFICA

Eduardo Matos Moctezuma, Historia de la Arqueología del México Antiguo, El Colegio Nacional: México, 2017, ISBN 9706401148 (Obra completa) ISBN 9786077242598 (Obras 8, primera parte), 456 páginas, ISBN 9786077242581 (Obras 8, segunda parte), 384 páginas.

\section{Jorge Maier Allende I Real Academia de Bellas Artes de San Fernando}

El Profesor Dr. Eduardo Matos Moctezuma es, sin duda, uno de los más prestigiosos arqueólogos mexicanos, avalado por una trayectoria profesional académica impecable que no está de más recordar. Ha sido director de la Escuela Nacional de Antropología e Historia (1917-1973), secretario general de la Sociedad Mexicana de Antropología (1971-1976), director general del Centro de Investigaciones y Estudios Superiores en Antropología Social (1983 a 1986), director del Museo Nacional de Antropología (1986-1987) y director fundador (1987-2000) del Museo del Templo Mayor, su más destacado proyecto arqueológico. Desde 1991 es coordinador del Programa de Arqueología Urbana. El Profesor Matos Moctezuma es asimismo miembro de la Academia Mexicana de la Historia, de la Academia Mexicana de la Lengua y del Colegio Nacional y su densa y prolija obra ha sido reconocida con varios premios y distinciones por las más prestigiosas instituciones, dentro y fuera de México. 
En el conjunto de su obra la historia de la arqueología mexicana ha sido también objeto de su atención en diversas ocasiones. Esta Historia de la Arqueología del México antiguo es su última aportación. Sin embargo, está edición es el resultado más completo de otras tentativas anteriores. Nos referimos a la Breve historia de la arqueología en México (1992) y Arqueología del México antiguo (2010). Huelga decir que está versión es la más completa y actualizada que se haya escrito hasta el momento de la arqueología mexicana, por lo que su lectura resulta imprescindible para toda persona interesada en la historia de la Arqueología con mayúsculas.

La obra se compone de dos volúmenes y está estructurada según un adecuado y estricto orden cronológico que arranca en el pasado de los pueblos prehispánicos y concluye prácticamente en nuestros días. Qué duda cabe que los antiguos pueblos mesoamericanos tuvieron una clara conciencia y se interesaron, de acuerdo a sus propios parámetros, por su pasado, como también ocurrió en otras grandes civilizaciones antiguas. Un aspecto realmente novedoso no muy atendido en otras historias de la Arqueología lo constituye el punto de partida del primer volumen de esta densa obra. Continua el profesor Matos Moctezuma analizando el impacto de los colonizadores españoles y las valiosas aportaciones de los distintos cronistas, tanto exógenos como endógenos, para el conocimiento del México antiguo, durante el siglo XVI y la primera mitad del XVII. Se podría decir que su legado, una fuente primordial, se podría considerar al modo de unas Fontes mexicanae antiquae, emulando a las que griegos y romanos dejaron, por ejemplo, sobre los antiguos pueblos ibéricos, los testimonios de aquellos que en definitiva vieron aquellas culturas vivas.

Resulta particularmente interesante el enfoque del siguiente capítulo, que discurre entre la segunda mitad del siglo XVII y la primera del XVIII, con el despertar de una nueva sensibilidad entre diversos eruditos anticuarios por su propio su legado cultural. Destacan entre ellos las aportaciones de Carlos de Sigüenza y Góngora, Antonio de Solís y Rivadeneyra y Lorenzo Boturini, ya en las puertas de la Ilustración.

Periodo de gran relevancia es el de la segunda mitad del XVIII, que muy acertadamente prolonga el profesor Matos hasta la época de la independencia, en el primer tercio del XIX, y al que titula con el significativo nombre de «La Ilustración o el retorno de los dioses». Ciertamente fue esta una época crucial de la arqueología mexicana con personalidades de muy diversa índole que enriquecieron notablemente el conocimiento del México antiguo, impulsadas a uno y otro lado del océano. La Arqueología dio un salto cualitativo desde las excavaciones emprendidas en las antiguas ciudades napolitanas de Herculano y Pompeya por Carlos III, la creación de un marco institucional con la fundación de Academias y Gabinetes de Historia Natural, que le confirieron una marcado carácter hispánico y universal a la Arqueología al alcanzar el continente americano, no exentas de subjetivas críticas alimentadas por la denominada «leyenda negra». Personalidades destacadas de esta universalización de la Arqueología fueron Antonio de Ulloa, Francisco Javier Clavijero, José Antonio de Alzate, Pedro José Márquez, Fray Servando Teresa de Mier y especialmente, Antonio León y Gama, para culminar con el gran naturalista Alexander von Humboldt y la Real Expedición Anticuaria de México del capitán Guillermo Dupaix. Con ellas la arqueología del México antiguo entró de lleno en el mundo científico internacional. 
El convulso periodo que se abrió con la independencia de México y transcurre hasta el Porfiriato es el tema del siguiente capítulo. Dada la densidad del mismo hubiera sido quizá deseable, desde nuestro punto de vista, haberlo desdoblado, de acuerdo a la propia evolución general de la disciplina, antes y después de la intervención francesa. La dinámica de la evolución de la disciplina durante este periodo bascula entre el desarrollo de la identidad nacional y la presencia de viajeros y estudiosos extranjeros, fundamentalmente ingleses y franceses. Respecto a la primera es de destacar la creación del Museo Nacional de Antigüedades en 1825 y las primeras medidas de protección del rico patrimonio arqueológico mexicano. En relación a la segunda recoge Matos Moctezuma las distintas expediciones y estudios de William Bullock, del conde de Waldeck, de John Lloyd Stephens y Frederick Catherwood, Carl Nebel, Mathieu de Fossey y William Prescott, que proyectaron la arqueología mexicana a nivel internacional. A nivel nacional destaca la labor de José Fernando Ramírez, director del Museo Nacional de Antigüedades y de la Biblioteca Nacional.

Con la intervención francesa a partir de 1863 se inicia en realidad otro subperiodo en el que se crea la Comisión Científica, Literaria y Artística de México y tuvieron lugar las intervenciones y los viajes de Charles Etienne Brasseur de Bourbourg, de escaso valor, y las de Desiré Charnay de mayor interés al utilizar la fotografía. A nivel nacional sobresale la labor, fundamentalmente filológica y documental, de Joaquín García de Izcabaleta y Manuel Orozco Berra. Finalmente llama Matos la atención sobre importantes hitos en la evolución de la disciplina, como el surgimiento del sistema de las tres edades, el evolucionismo o la antropología arqueológica, que, no obstante, tuvieron poco impacto en México: «Sin embargo los adelantos que se daban en Europa desde la perspectiva de la ciencia no encontraron eco en los sabios locales». Es este un aspecto llamativo, ya que nos anuncia el carácter peculiar con que se desarrollará la disciplina en etapas consecutivas, que la alejaran de la arqueología europea.

Con la llegada de Porfirio Díaz al poder se inicia un nuevo periodo (1877-1911) y el último correspondiente al primer volumen, caracterizado en líneas generales por el fin de la inestabilidad política y la introducción del positivismo, que tendrán un claro reflejo a nivel institucional. Destaca el profesor Matos varios hechos importantes que denotan una mayor intervención estatal. Por una parte, la creación de una Inspección de Monumentos en 1885, bajo la dirección del arqueólogo Leopoldo Batres -arqueólogo oficial del Porfiriato-, la ley de monumentos arqueológicos de 11 de mayo de 1897 y la expropiación de los terrenos de Teotihuacán. Pero llama también la atención sobre otros acontecimientos importantes como la creación de la Comisión Colombina con motivo del IV centenario del descubrimiento, las excavaciones de Batres en Teotihuacán y la creación del primer museo de sitio y la creación de la Escuela Internacional de Arqueología y Etnología Americanas, en 1911 bajo los auspicios de The Hispanic Society y las Universidades de Harward, Pennsylvania y Columbia. No obstante, el primer centro docente fue el Museo Nacional y la creación de los Anales del Museo Nacional de México su principal órgano de difusión. En su seno destacaron figuras como Francisco del Paso y Troncoso y Jesús Galindo y Villa. Pero en este tiempo se fundaron también otros museos entre los que destaca el de Michoacán dirigido por Nicolás León, que contó con los Anales del 
Museo Michoacano, así como en Mérida, San Luis, Colima y Oaxaca. El panorama docente se completa con la refundación de la Universidad de México en 1910.

Las intervenciones extranjeras fueron también importantes en este periodo por parte de instituciones norteamericanas como la Smithsonian, el Peabody Museum o la Carneige Institution de Washington. Destaca las intervenciones de Alfred Percival Maudsley, que trabajó en el área maya y fue el iniciador del desciframiento de su escritura y calendario, y las de Edward Seler, director de la sección americana del Museo Etnográfico de Berlín, quien desarrolló importantes trabajos sobre los mitos, religión y lengua de los mayas y determinó el sistema calendárico azteca. A nivel nacional describe por extenso las actividades de Leopoldo Batres, Inspector y Conservador de Monumentos Arqueológicos de la República.

Concluye Matos este interesante capítulo, señalando que no existe unanimidad a la hora de denominar este periodo, pero resalta la importancia de la creación de la Escuela Internacional de Arqueología y Etnología Americanas, en la que destaca la presencia de dos personalidades de gran relevancia como fueron las de los antropólogos alemanes Franz Boas (1858-1942) y Edward Seler (1849-1922), que fueron determinantes en la evolución de la arqueología mexicana y el peso que, a partir de entonces, tuvo la Antropología en sus peculiares rasgos definitorios, coherente en un país que tiene una de las mayores poblaciones indígenas del continente americano.

El volumen segundo está dedicado exclusivamente al siglo XX que lógicamente también está estructurado cronológicamente. El primer capítulo se centra en el periodo comprendido entre 1911 y 1925 y se dedica precisamente a la influencia de la Escuela Internacional y de Franz Boas, que fue su director entre 1911 y 1912, y su máximo exponente a nivel nacional Manuel Gamio Martínez (1883-1960). De gran importancia también fue la adopción generalizada de la estratigrafía y el estudio sistemático de la cerámica como elemento de datación secuencial y caracterización regional. En realidad, Matos revaloriza enfáticamente este período, marcado por la revolución, al resaltar la variedad e importancia de las iniciativas y de los nuevos conceptos desarrollados, especialmente por Gamio, entre otros, y su concepción de la Arqueología como parte de la Antropología y su carácter esencialmente interdisciplinar, que puso en práctica en sus intervenciones desde la Dirección de Antropología, y que quedaron plasmadas en su obra más destacada La población del valle de Teotihuacán.

La consolidación de la Arqueología antropológica o la Antropología arqueológica constituye el punto central del siguiente capítulo en el que analiza los veinticinco años que median entre 1925 y 1950, marcados a nivel científico por la sistematización de la cerámica y la personalidad de, en palabras de Matos de «uno de los arqueólogos de más renombre» Alfonso Caso Andrade (1896-1970).

La institucionalización de la Antropología se produjo a través de la creación de diversos centros de investigación creados bajo el mandato presidencial de Lázaro Cárdenas. En 1937 nacía la Sociedad Mexicana de Antropología y dos años después, en 1939, lo hacía el Instituto Nacional de Antropología e Historia (INAH), institución clave de la arqueología mexicana. Este último, como parte de la Secretaría de Educación Pública, tiene como función «la salvaguarda, estudio y difusión de los sitios arqueológicos, artísticos e históricos, además de llevar a cabo investigaciones de carácter antropológico». A esta institución se incorporó la Escuela 
Nacional de Antropología e Historia (ENAH), principal centro de formación de especialistas. Por último, en 1943, se creó El Colegio Nacional, institución en la que se agrupan los más destacados científicos, artistas y literatos, en el que figuraron y figuran varios arqueólogos, entre ellos el mismo Matos Moctezuma.

En el plano estrictamente científico, uno de los hechos más relevantes de este periodo fue la definición, a partir de la cultura material y factores económicos, sociales y religiosos, del concepto de «Mesoámerica» por Paul Kirchhoff (1900-1972), quien llegó a México en 1937 y fue cofundador de la ENAH.

Todo ello dio lugar a una intensificación cualitativa y cuantitativa de las investigaciones, aunque en principio no tanto desde el punto de vista metodológico y técnico. Nos ofrece Matos una completa síntesis de los trabajos llevados a cabo en este periodo, comenzando por la civilización Olmeca, para continuar un recorrido geográfico por las distintas regiones mesoamericanas definidas arqueológicamente: el Centro de México (Cuicuilco, Tlatilco, Teotihuacán, Cholula, Xochicalco, Tula, Tenayuca, Tenochtitlán y Tlatelolco, entre otros); Oaxaca (Monte Albán, Mitla); el Sureste, es decir, la zona maya, donde la actividad fue especialmente intensa por investigaciones estadounidenses (Uaxactún, Tikal, Nakum, Quiriguá, Copán, Kaminaljuyú, Izapa, Chiapa el Corzo, Yaxchilán, Toniná, Palenque, Bonampak, Calakmul, Comalcalco, Edzná, Uxmal, Tulum o Chichen Itzá). Continúa Matos su recorrido por la Costa del Golfo en lugares huastecos y totonacos, entre los que destaca El Tajín, para finalizar con el Occidente de México (Culiacán, Tzintzuntzan, El Opeño) y el Norte de Mesoamérica (La Quemada y Chalchihuites). Estos trabajos fueron llevados a cabo por los arqueólogos mexicanos Alfonso Caso, Román Piña Chan, José García Payón, Wigiberto Jiménez Moreno, Paul Kirchoff, Daniel Rubín de la Borbolla y Miguel Othón de Mendizábal y por los investigadores estadounidenses Mathew W. Sterling, Alfred Kroeber, Sylvanus Griswold Morley y Alfred V. Kiedder, entre otros.

El tercer y último capítulo de este volumen está dedicado a los avatares de la arqueología mexicana desde 1950 hasta las puertas del siglo XXI. Centra en primer lugar su atención tanto en las nuevas técnicas aplicadas en la Arqueología (prospección, sistemas de datación, arqueobotánica, informática) como en las nuevas tendencias teóricas a partir de las ideas de Gordon Childe, el materialismo histórico y la Nueva Arqueología y su plasmación en diferentes corrientes. Hay que tener en cuenta que Matos Moctezuma es ahora un investigador activo en este periodo, lo que le permite ilustrar este periodo desde un agudo sentido crítico. A continuación, describe distintos proyectos arqueológicos atendiendo a las nuevas técnicas empleadas: la fotografía aérea, generalizada a partir de la Segunda Guerra Mundial, y las prospecciones superficiales con sondeos estratigráficos, que han proporcionado importantes resultados en la identificación de yacimientos y los patrones de asentamiento, así como espectaculares descubrimientos. La mayor parte de estas investigaciones fueron llevadas a cabo por equipos de investigación extranjeros, estadounidenses, canadienses, alemanes y franceses, aunque también belgas y españoles. Bajo esta perspectiva describe pormenorizadamente las que denomina de «rescate o salvamento arqueológico» como consecuencia de las obras públicas de infraestructuras energéticas, de comunicación, inmobiliarias etc. Estas fueron llevadas a cabo, a partir de los años 60', por el INAH, institución que tuvo, de acuerdo a su naturaleza, la prioridad de intervención desde la ley de 1972, que han revestido particular 
importancia en la Ciudad de México y han culminado con la creación por el propio Matos Moctezuma del Programa de Arqueología Urbana instaurado en 1991. También destaca otras intervenciones singulares en las que, no obstante, alternaron los enfoques tradicionalistas, de reconstrucción monumental, con los interdisciplinares. Tal es el caso del proyecto de Teotihuacán, coordinado por Ignacio Bernal (1910-1991) entre 1962-1964, del proyecto Cholula desarrollado entre 1966 y 1968 o el proyecto Prehistoric Human Ecology de Kent Flannery y sus colaboradores, entre otros.

Hito de primer orden de la arqueología mexicana en este periodo lo constituye el Proyecto Templo Mayor dirigido por Matos Moctezuma a partir de 1978. Nos encontramos, sin duda, ante uno de los más importantes proyectos para la arqueología azteca realizados hasta la fecha, complementado desde 1991 con el ya mencionado programa de arqueología urbana. Como señala Matos: «El Proyecto Templo Mayor es la investigación arqueológica multidisciplinar que cuenta con un mayor número de publicaciones en la historia de la arqueología».

Por último, aborda la descripción de los llamados Proyectos especiales de Arqueología desarrollados por el INAH entre 1992 y 1994 que contaron «con una derrama económica sin precedentes por parte del gobierno federal». La iniciativa consistió en la selección de diversos yacimientos escogidos según diferentes criterios con el fin de desarrollar campañas de excavación y creación de museos. Entre ellos cabe destacar las intervenciones en Teotihuacán, Xochitecate (Tlaxcala), Xochicalco (Morelos), Cantona (Puebla), Monte Albán (Oaxaca), Filobobos (Veracruz), Palenque (Chiapas), Toniná (Chiapas), Calakmul (Campeche), Chichén Itzá (Yucatán), sur de Quintana Roo y las pinturas rupestres de la Baja California.

Durante este periodo surgieron un nuevo elenco de centros de investigación que han enriquecido y reforzado espectacularmente el panorama institucional. Cabe destacar el Instituto Veracruzano de Antropología y la Facultad de Antropología de la Universidad Veracruzana, el Instituto de Investigaciones Antropológicas, del que formó parte, entre otros, Pedro Bosch Gimpera, el Instituto de Investigaciones Históricas, el Instituto de Investigaciones Estéticas y el Instituto de Investigaciones Filológicas, al que está adscrito el Centro de Estudios Mayas, todos ellos encuadrados en la Universidad Nacional Autónoma de México. También cabe mencionar la Universidad de las Américas de Puebla y los nuevos centros adscritos del INAH: el Centro de Restauración de Bienes Culturales, la Subdirección de Arqueología Subacuática y el Consejo de Arqueología. La obra se cierra con una sugestiva reflexión final.

La Historia de la Arqueología del México Antiguo nos ofrece por tanto un prolijo recorrido por la génesis, desarrollo y avatares de la arqueología mexicana, descrito desde un profundo conocimiento de su historia, pero también desde la propia experiencia vital del Profesor Matos Moctezuma. La obra viene, sin duda, a sustituir a las ya clásicas Historia de la Arqueología en México de Ignacio Bernal (1979) o A History of American Archaeology de Gordon R. Willey y Jeremy A. Sablaoff (1974). Redactada con un lenguaje vivo y entretenido, asequible y dinámico, esta profusamente ilustrada y cuenta con un orientativo y útil aparato bibliográfico, así como de un índice onomástico y toponímico que son siempre de agradecer en una obra de semejante magnitud. 